\title{
Piperidine Containing Murrayanine-Chalcones as Emerging Bactericidal and Fungicidal Agents
}

\author{
Debarshi Kar Mahapatra $^{1^{*}}$, Ruchi S. Shivhare ${ }^{2}$, Ajmal R. Bhat ${ }^{3}$ \\ ${ }^{1}$ Department of Pharmaceutical Chemistry, Dadasaheb Balpande College of Pharmacy, Nagpur 440037, Maharashtra, India \\ ${ }^{2}$ Department of Pharmaceutical Chemistry, Kamla Nehru College of Pharmacy, Nagpur 441108, Maharashtra, India \\ ${ }^{3}$ Department of Chemistry, Government Degree College, Bijbehara 192124, Jammu and Kashmir, India
}

*Corresponding author: Debarshi Kar Mahapatra, Department of Pharmaceutical Chemistry, PhD, Assistant Professor, Dadasaheb Balpande College of Pharmacy, Nagpur 440037, Maharashtra, India, E-mail: dkmbsp@gmail.com

\begin{abstract}
Among the 20 other alkaloid molecules, murrayanine is the highest explored alkaloidal component present in the curry plant (Murraya koenigii L.). In the current research, a piperidine containing chalcone [(E)-1-(1-methoxy-9H-carbazol3-yl)-3-(4-(piperidin-1-yl)phenyl)prop-2-en-1-one] was rationally developed by incorporating the natural portion (murrayanine) in the A-ring and a synthetic component (1-(4-(piperidin-1-yl)phenyl)ethanone, a piperidine containing acetophenone) in the B-ring and screened against two bacterial species (Escherichia coli and Staphylococcus aureus) and two fungal species (Candida albicans and Aspergillus niger). The chalcone (1, 3-diphenyl-2E-propene-1-one) candidate expressed a better anti-bacterial activity than that of anti-fungal activity. The chalcone displayed the highest activity against E. coli followed by $S$. aureus, and lowest against $C$. albicans. Although, were found to have less activity and potency than that of the standard compounds (ciprofloxacin and fluconazole). The current study will open new avenues of research on hybrid heterocyclic chalcones and will motivate researchers to further developing highly active compounds based on benzylideneacetophenone scaffold.
\end{abstract}

Keywords: Murraya koenigii; Murrayanine; Chalcone; Piperidine; Antifungal; Antibacterial

\section{Introduction}

The benzylideneacetophenone or 1, 3-diphenyl-2E-propene-1one or chalcone is one of the most emerging scaffolds which is present in nature abundantly. It is believed to be an open chain intermediate in aurone synthesis of flavones pathway and also play a pivotal role in the natural synthesis of is of lavonoids and flavonoids ${ }^{[1]}$. The molecules of chalcone scaffold have been reported to express anti-inflammatory, anti-diabetic, anti-gout, anti-hypertensive, anti-retroviral, anti-oxidant, anti-tubercular, anti-angiogenic, anti-malarial, anti-neoplastic, anti-protozoal, anti-bacterial, anti-arrhythmic, anti-histaminic, anti-platelet, anti-fungal, anti-ulcer, anti-filarial, hypolipidemic, and anti-obesity $^{[2-6]}$. Murrayanine is a carbazole containing natural product obtained from Murraya koenigii L. (Family: Rutaceae), having ethnopharmacological importance like immunomodulation, astringent, anti-oxidant, febrifuge, purgative, anti-helminthic, anti-ulcerogenic, etc. In the modern studies related to Murraya koenigii and its carbazole containing active principles, activities such as anti-diabetic, anti-oxidant, anti-inflammatory, anti-infective, etc ${ }^{[7]}$. Among the 20 other alkaloid molecules, murrayanine is the highest explored alkaloidal component present in the curry plant. Very recently, we have explored the pharmacological perspectives of the semi-synthetic products of this molecule and rationally developed the heterocyclic hybrids of murrayanine such as benzodiazepine ${ }^{[8]}$, benzothiazepine ${ }^{[9]}$, benzoxazepine ${ }^{[10]}$, chalcone $^{[11-14]}$, hydantoin ${ }^{[15]}$, imidazole ${ }^{[16]}$, isoxazole ${ }^{[17]}$, oxadiazole $^{[18]}$, phthalimide ${ }^{[19]}$, pyrazole ${ }^{[20]}$, pyrimidine ${ }^{[21]}$, Schiff's base analog ${ }^{[22]}$, thiadiazole ${ }^{[23]}$, thiazole ${ }^{[24]}$, and uracil ${ }^{[25-27]}$, and explored multifarious pharmacological activities such as anxiolytic, anti-cancer, anti-convulsant, anti-inflammatory, anti-microbial, anti-oxidant, etc. Likewise, in the current research, a piperidine containing chalcone was rationally developed by incorporating the natural portion (murrayanine) in the A-ring and a synthetic component (piperidine containing acetophenone) in the B-ring and screened against bacterial and fungal species.

Received date: October 28, 2018

Accepted date: November 6, 2018

Publish date: November 11, 2018

Citation: Mahapatra, D.K., et al. Piperidine Containing Murrayanine-Chalcones as Emerging Bactericidal and Fungicidal Agents (2018) J Pharm Pharmaceutics 5(2): 88- 91.

Copyright: (C) 2018 Mahapatra, D.K. This is an Open access article distributed under the terms of Creative Commons Attribution 4.0 International License. 


\section{Materials and Methods}

Chemicals and instrumentation: The reactant 1-(4-(piperidin-1-yl) phenyl) ethanone was procured from Sigma Aldrich, Germany. The analytical grade chemicals, solvents, and reagents were purchased from HiMedia Ltd., India. The structural elucidation was performed on Fourier transformed Infrared Spectroscopy (Shimadzu ${ }^{\circledR}$ IR-Affinity-1), Mass Spectroscopy (MICROMASS Q-TOF), and ${ }^{1} \mathrm{H}-\mathrm{NMR}$ Spectroscopy (Bruker Avance-II). Merck ${ }^{\circledR}$ Silica gel-G pre-coated TLC plates were utilized to monitor the progress of the chemical reaction. The PerkinElmer 2400 model Elemental Analyzer was employed for the $\mathrm{CHN}$ analysis.

Extraction of murrayanine: Murrayanine was extracted from the M. koenigii powdered stem bark as per our previously developed method ${ }^{[7]}$. The extraction was performed on a silica gel-based column by using n-hexane mobile phase. The obtained hexane fractions $\left(\mathrm{B}_{21}-\mathrm{B}_{37}\right)$ were scrutinized by thin layer chromatography and concentrated further by the vacuum rotary evaporator.

Synthesis of target compounds: The synthesis of benzylideneacetophenone (chalcone) scaffold (3) comprising the $\beta$-hydroxyketone function involved an aldol condensation mechanism where the $-\mathrm{CHO}$ (aldehyde) portion of the starting material murrayanine (1) reacts with the $-\mathrm{COCH}_{3}$ (acetyl) part of the piperidine containing acetophenone (2) in the presence of ethanolic $\mathrm{NaOH}$ solution (Scheme 1).

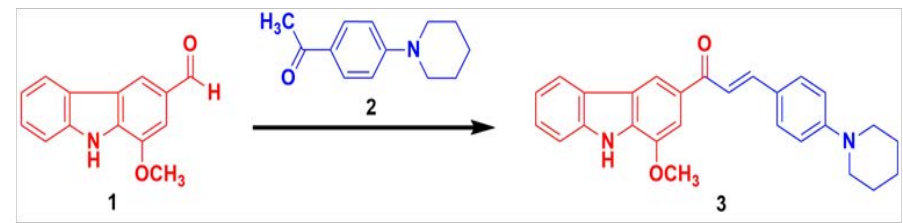

Scheme 1. Fabrication of piperidine containing murrayanine-chalcone based compound.

Synthetic protocol for (E)-1-(1-methoxy-9H-carbazol-3-yl)3-(4-(piperidin-1-yl) phenyl) prop-2-en-1-one: An equimolar concentration $(0.01 \mathrm{M})$ of the starting material murrayanine (1) and the reactant 1-(4-(piperidin-1-yl)phenyl)ethanone (2) were made to reflux in the presence of $20 \mathrm{~mL}$ aqueous solution of sodium hydroxide containing $25 \mathrm{~mL}$ of $90 \%$ ethanol. The reaction mixture was made to stand overnight. The content was poured over crushed ice containing dilute $\mathrm{HCl}$ (a few drops) and stirred vigorously using a glass rod. The obtained product (3) was separated by filtration, thoroughly washed, and suitably recrystallized.

$45 \%$ yield; FTIR (KBr) v ( $\left.\mathrm{cm}^{-1}\right): 3260$ (-NH, stretching), 3078 (C-H, aromatic), $1727(\mathrm{C}=\mathrm{O}), 1622(\mathrm{C}=\mathrm{C}$, aromatic), 1601 (-NH, bending), 1319 (C-N), 1198 (C-O); ${ }^{1} \mathrm{H}$ NMR $(\delta, \mathrm{ppm}$, $\left.\mathrm{CDCl}_{3}\right): 10.22(9,1 \mathrm{H}), 6.8-8.2$ (Aromatic, $\left.10 \mathrm{H}\right), 3.99(1,3 \mathrm{H})$, $3.61(18,2 \mathrm{H}), 1.67(19,2 \mathrm{H})$. MS: $\mathrm{M}^{+}$410. Anal. Calcd. For $\mathrm{C}_{27} \mathrm{H}_{26} \mathrm{~N}_{2} \mathrm{O}_{2}$ : C, 79.00; H, 6.38; N, 6.82. Found: C, 78.06; H, $6.09 ; \mathrm{N}, 6.71$.
Anti-microbial screening: The developed piperidine containing chalcone was screened by using disc diffusion method against Staphylococcus aureus (S. aureus, MTCC 3160) and Escherichia coli (E. coli, MTCC 2961) [anti-bacterial, by utilizing Muller Hinton Agar medium and incubation at $37 \pm 1^{\circ} \mathrm{C}$ for $24 \mathrm{hrs}$ ] and Aspergillus niger (A. niger, MTCC 277) and Candida albicans (C. albicans, MTCC 227) [anti-fungal, by utilizing Potato Dextrose Agar medium and incubation at $37 \pm 1^{\circ} \mathrm{C}$ for $72 \mathrm{hrs}$ ]. The nutrient broth media was initially employed for culturing the microbial species at $37 \pm 1^{\circ} \mathrm{C}$ for $24 \mathrm{hr}$, which was followed by specifically transferring them into the agar plates under laminar air flow. The chalcone in dimethyl sulfoxide (DMSO) was soaked over Whatman filter paper, carefully placed over the microbial plates and incubated. The ciprofloxacin was utilized as the positive control for anti-bacterial screening, the fluconazole served an analogous function for the anti-fungal screening, and DMSO was employed as the negative control ${ }^{[28]}$. The agar streak dilution method was employed for the estimation of MIC (Minimum Inhibitory Concentration). For the determination, a 105 CFU / $\mathrm{mL}$ microbial suspension was prepared and serial dilution was applied with DMSO. The test sample containing suspension in required quantity was transferred into the petri dish to $5 \mathrm{~mm}$ depth at $40-50^{\circ} \mathrm{C}$ temperature. The average of MIC value was taken into account. The ciprofloxacin was utilized as the positive control for anti-bacterial screening, the fluconazole served analogous function for the anti-fungal screening, and DMSO was employed as the negative control ${ }^{[29]}$.

\section{Results and Discussion}

Chemistry: The spectroscopic studies helped in elucidating the structure of piperidine containing chalcone compound. The FTIR spectra confirmed the formation of a new ketonic carbonyl group at $1727 \mathrm{~cm}^{-1}$ and disappearance of the aldehydic carbonyl group which was earlier noticed at $1753 \mathrm{~cm}^{-1}$. In addition to it, the proton-NMR focused on some imperative aspects of the structure. The aromatic protons were distinctly located in the range of $6.8-8.2 \mathrm{ppm}$. The methoxy protons were discerned from the peak at $3.99 \mathrm{ppm}$ which furthermore substantiated the presence of heterocyclic carbazole moiety in the structure as well as the unification of the two aromatic sections in the molecule. The piperidine heterocycle was particularly distinguished by the peaks at $3.61 \mathrm{ppm}$ (position 18) and $1.67 \mathrm{ppm}$ (position 19). The fabrication of the chalcone derivative was ascertained from the mass spectra which revealed the emergence of the base peak corresponding with the molecular mass of the molecule along with some fragmented products with $\mathrm{m} / \mathrm{z}$ of $<100$. The ratios of $\mathrm{CHN}$ analysis demonstrated a close agreement with the theoretical values and certainly supported the formation of the prop-2-en-1-one compound.

Anti-microbial study: A noteworthy anti-microbial effect was observed for the novel piperidine-containing chalcone compound. The molecule expressed a better anti-bacterial activity than that of anti-fungal potential. Even though, the potential and potency of the chalcone were perceived to be less than that of the standard compounds (ciprofloxacin and fluconazole). The chalcone displayed the highest activity against $E$. coli followed by $S$. aureus, and lowest against C. albicans (Table 1). However, the 
Citation: Mahapatra, D.K., et al. Piperidine Containing Murrayanine-Chalcones as Emerging Bactericidal and Fungicidal Agents (2018) J Pharm Pharmaceutics 5(2): 88- 91 .

difference and variability (Inter and Intra) were found to be quite minor. An anti-infective perspective of the fabricated heterocycle containing chalcone was observed from this study.

Table 1: Anti-microbial perspectives of piperidine containing chalcone.

\begin{tabular}{|l|l|l|l|l|}
\hline $\begin{array}{l}\text { Com- } \\
\text { pounds }\end{array}$ & E. coli & S. aureus & A. niger & C. albicans \\
\hline 3 & $\begin{array}{l}22.71 \pm 1.29 \\
(25)\end{array}$ & $\begin{array}{l}20.52 \pm 1.88 \\
(25)\end{array}$ & $\begin{array}{l}19.37 \pm 1.91 \\
(25)\end{array}$ & $\begin{array}{l}16.89 \pm 1.46 \\
(25)\end{array}$ \\
\hline $\begin{array}{l}\text { Ciproflox- } \\
\text { acin }\end{array}$ & $\begin{array}{l}33.16 \pm 1.63 \\
(6.25)\end{array}$ & $\begin{array}{l}31.09 \pm 1.31 \\
(6.25)\end{array}$ & - & - \\
\hline $\begin{array}{l}\text { Fluco- } \\
\text { nazole }\end{array}$ & - & - & $33.84 \pm 1.33$ & $\begin{array}{l}32.16 \pm 1.97 \\
(6.25)\end{array}$ \\
\hline
\end{tabular}

Zone of inhibition in millimeter, $\mathrm{SD}=$ standard deviation.

\section{Conclusion}

The developed chalcone molecule; $(E)-1-(1-$ methoxy-9H-carbazol-3-yl)-3-(4-(piperidin-1-yl)phenyl)prop-2-en-1-one comprising of a natural product murrayanine in ring-A and a heterocycle (piperidine) containing portion in ring-B, displayed noteworthy anti-microbial against E. coli, S. aureus, A. niger, and C. albicans. The chalcone candidate expressed a better anti-bacterial activity than that of anti-fungal activity. Although, were found to have less activity and potency than that of the standard compounds (ciprofloxacin and fluconazole). The current study will open new avenues of research on hybrid heterocyclic chalcones and will motivate researchers in further developing highly active compounds based on benzylideneacetophenone scaffold.

\section{Acknowledgment}

Authors are highly thankful to Savitribai Phule Pune University, Pune, and Maharashtra, India for providing research grants (Grant No. 13PHM000126).

\section{Conflict of Interest}

No conflict of interest declared.

\section{References}

1. Mahapatra, D.K., Bharti, S.K., Asati, V. Recent perspectives of chalcone based molecules as protein tyrosine phosphatase 1B (PTP-1B) inhibitors. (2018) Apple Academic Press. Pubmed $\mid$ Crossref $\mid$ Others

2. Mahapatra, D.K., Bharti, S.K., Asati, V. Chalcone derivatives: Anti-inflammatory potential and molecular targets perspectives. (2017) Curr Top Med Chem 17(28): 31463169.

Pubmed |Crossref| Others

3. Mahapatra, D.K., Bharti, S.K., Asati, V. Anti-cancer Chalcones: Structural and molecular targets perspectives. (2015) Eur J Med Chem 98: 69-114.

Pubmed |Crossref| Others

4. Mahapatra, D.K., Bharti, S.K., Asati, V. Chalcone scaffolds as anti-infective agents: Structural and molecular target perspectives. (2015) Eur J Med Chem 101: 496-524.

Pubmed |Crossref| Others

5. Mahapatra, D.K., Asati, V., Bharti, S.K. Chalcones and their role in management of diabetes mellitus: Structural and pharmacological perspectives. (2015) Eur J Med Chem 92: 839-865.

Pubmed |Crossref| Others

6. Mahapatra, D.K., Bharti, S.K. Therapeutic Potential of chalcones as cardiovascular agents. (2016) Life Sci 148: 154-172.

Pubmed |Crossref| Others

7. Shivhare, R.S., Mahapatra, D.K., Nair, R.R., et al. Schiff's base derivatives of murrayanine demonstrated enhanced anti-oxidant activity than its parent moiety. (2016) Indian J Pharm Edu Res 50(4): 9-15.

Pubmed |Crossref| Others

8. Mahapatra, D.K., Shivhare, R.S., Dadure, K.M. Transforming Murrayanine-Chalcone into corresponding $3 \mathrm{H}-\mathrm{benzo}[\mathrm{b}]$ $[1,4]$ diazepine derivatives: Accessing the anti-anxiety effect by inhibition of locomotor activity. (2018) Acta Scientific Pharma Sci 2(5): 40-44.

Pubmed |Crossref| Others

9. Mahapatra, D.K., Shivhare, R.S., Asati, V. Locomotor inhibitory activity of some Murrayanine-Chalcone based 2, 3-dihydrobenzo[b][1, 4] thiazepine derivatives: Exploring Anxiolytic potentials. (2018) Chron Pharm Sci 2(1): 462468.

Pubmed |Crossref $\mid$ Others

10. Mahapatra, D.K., Shivhare, R.S., Gupta, S.D. Anxiolytic activity of some 2, 3-dihydrobenzo[b] [1, 4] oxazepine derivatives synthesized from Murrayanine-Chalcone. (2018) Asian J Res Pharm Sci 8(1): 25-29.

Pubmed |Crossref| Others

11. Mahapatra, D.K., Chhajed, S.S., Shivhare, R.S. Development of Murrayanine-Chalcone hybrids: An effort to combine two privilege scaffolds for enhancing hypoglycemic activity. (2017) Int J Pharm Chem Anal 4(2): 30-34.

Pubmed |Crossref| Others

12. Mahapatra, D.K., Shivhare, R.S. 3', 4'-Methylenedioxy Moiety Containing Murrayanine Based Chalcone as Emerging Anti-inflammatory Agent. (2018) J Mod Chem Chem Technol 9(1): 12-16.

Pubmed |Crossref| Others 
13. Mahapatra, D.K., Shivhare, R.S. Anti-microbial Perspective of a Chalcone, (E)-1-(1-methoxy-9H-carbazol-3-yl)-3-(4(methylsulfonyl) phenyl) prop-2-en-1-one: Fabrication of a Hybrid by Unification of a Natural Product with a Synthetic Component. (2018) Int J Agri Life Sci 4(2): 236-240. Pubmed |Crossref| Others

14. Mahapatra, D.K., Dadure, K.M., Shivhare, R.S. Exploring the Site-Specific Influence of Hydroxyl group in Ring-B of Murrayanine-Chalcone on Edema Reducing Potential. (2018) MOJ Drug Design Devel Ther 2(4): 191-193.

Pubmed |Crossref| Others

15. Mahapatra, D.K., Das, D., Shivhare, R.S., et al. Murrayanine-hydantoin and -thiohydantoin analogs as promising anti-convulsant agents: Synthesis, Characterization and Molecular Docking Studies. (2018) MOJ Bioorg Org Chem 2(2): 47-51.

Pubmed |Crossref| Others

16. Mahapatra, D.K., Shivhare, R.S. Anti-inflammatory Potential of a Novel Imidazole Containing Murrayanine Based Chalcone. (2018) Mod Appl Pharm Pharmacol 2(2): 1-4. Pubmed |Crossref| Others

17. Mahapatra, D.K., Shivhare, R.S., Joseph, T.M. Design and characterization of Murrayanine linked Isoxazole derivatives: Novel class of bacteriocidal agents. (2017) Int J Res Drug Pharm Sci 1(1): 11-15.

Pubmed |Crossref| Others

18. Mahapatra, D.K., Shivhare, R.S., Ugale, V.G. Anti-inflammatory potentials of some novel Murrayanine containing 1, 3, 4-Oxadiazole derivatives. (2018) Asian J Pharm Technol 8(1): 47-51.

Pubmed |Crossref| Others

19. Mahapatra, D.K., Shivhare, R.S. Synthesizing an anti-oxidant principle 2-(((1-methoxy-9H-carbazol-3-yl) methylene) amino) isoindoline -1, 3-dione from $\mathrm{N}$-aminophthalimide and murrayanine. (2017) Inventi Med Chem 2017(4): 1-3.

Pubmed |Crossref| Others

20. Mahapatra, D.K., Shivhare, R.S., Bharti, S.K. Novel Murrayanine based Pyrazole analogs as emerging anti-fungal candidates: Design, synthesis, characterization, and in vitro evaluation. (2017) Res Pharm 1(1): 1-5.

Pubmed |Crossref] Others

21. Mahapatra, D.K., Shivhare, R.S., Kumar, P. Murrayanine-chalcone transformed into novel pyrimidine compounds demonstrated promising anti-inflammatory activity. (2018) Asian J Pharm Res 8(1): 6-10.

Pubmed |Crossref| Others
22. Mahapatra, D.K., Dadure, K.M., Shivhare, R.S. Edema Reducing Potentials of Some Emerging Schiff's bases of Murrayanine. (2018) MOJ Bioorg Org Chem 2(4): 172-175. Pubmed |Crossref| Others

23. Mahapatra, D.K., Shivhare, R.S., Haldar, A.G.M. Novel Schiff's base containing Murrayanine-1, 3, 4-Thiadiazole Hybrids as potential anti-inflammatory agents. (2017) Asian J Chem Pharm Sci 2(2): 27-32.

Pubmed |Crossref| Others

24. Mahapatra, D.K., Das, D., Shivhare, R.S. Substituted thiazole linked murrayanine-Schiff's base derivatives as potential anti-breast cancer candidates: Future EGFR Kinase inhibitors. (2017) Int J Pharm Sci Drug Res 9(3): 139-144. Pubmed |Crossref| Others

25. Mahapatra, D.K., Ugale, V.G., Shivhare, R.S. Murrayanine-1, 3, 4-Oxadiazole-Uracil Hybrid: The Emerging Anti-inflammatory Candidate. (2018) Int J Pharm Sci Res 9(8): 99-102.

Pubmed |Crossref $\mid$ Others

26. Mahapatra, D.K., Dadure, K.M., Shivhare, R.S. Murrayanine-1, 3, 4-Thiadiazole-Uracil Hybrid as Emerging Anti-inflammatory Candidate. (2018) Madridge J Novel Drug Res 2(1): 75-78.

Pubmed |Crossref| Others

27. Mahapatra, D.K., Dadure, K.M., Shivhare, R.S. MCF-7 cell line screening of some uracil containing murrayanine based (thio)-semicarbazide hybrids. (2018) Innovat Int J Med Pharm Sci 3(5): 14-16.

Pubmed |Crossref $\mid$ Others

28. Kamble, M.A., Mahapatra, D.K., Dhabarde, D.M., et al. Pharmacognostic and pharmacological studies of Bombax ceiba thorn extract. (2017) J Pharm Pharmacog Res 5(1): 40-54.

Pubmed |Crossref| Others

29. Telrandhe, R., Mahapatra, D.K., Kamble, M.A. Bombax ceiba thorn extract mediated synthesis of silver nanoparticles: Evaluation of anti - Staphylococcus aureus activity. (2017) Int J Pharm Drug Anal 5(9): 376-379. Pubmed |Crossref| Others

Submit your manuscript to Ommega Publishers and we will help you at every step:

- We accept pre-submission inquiries

- Our selector tool helps you to find the most relevant journal

- We provide round the clock customer support

- Convenient online submission

- Thorough peer review

- Inclusion in all major indexing services

- Maximum visibility for your research

Submit your manuscript at OMMEgA Publishers https://www.ommegaonline.org/submit-manuscript 